\title{
Giant Adrenal Myelolipoma: Is Laparoscopic Resection Possible?
}

\author{
Sara Lourenço, Catarina Osório, Rui Almeida, Marta Guimarães, Mário Nora \\ Department of General Surgery, Centro Hospitalar Entre Douro e Vouga, Portugal.
}

\section{Corresponding Author:}

Dr Sara Ferreira Pinto Lourenço

Email: sarafplourenco@gmail.com

This is an Open Access article distributed under the terms of the Creative Commons Attribution License (creativecommons.org/ licenses/by/3.0).

Received : December 7, 2019

Accepted : June 28, 2020

Published : July 10, 2020

\begin{abstract}
Background: Myelolipoma is a benign and uncommon tumor of the adrenal gland. The majority is small and asymptomatic and is diagnosed incidentally. However it can be large and produce symptoms. The laparoscopic adrenalectomy is the gold standard for its treatment but can be challenging if the lesion is big because of technical aspects and the associated malignancy risk. Case Report: We present a case of an asymptomatic 37 years old man, with past history of arterial hypertension, that performed an abdominal ultrasound that showed a huge mass on the right adrenal gland with $98 \times 85 \times 96 \mathrm{~mm}$, consistent with a myelolipoma. The abdomino-pelvic tomography confirmed the diagnosis and the functional study revealed a marginal elevation of plasmatic nor-adrenaline and catecholamines. The MIBG scintigraphy was normal. The lesion was removed by laparoscopy. Conclusion: The giant adrenal myelolipoma is a rare tumor. Laparoscopic adrenalectomy has become the gold standard in management of most adrenal masses. Even for giant adrenal masses, it can be done in a safe way, provided that is performed by an experienced laparoscopic team.
\end{abstract}

Keywords: Adrenal Gland Neoplasms, Adrenalectomy, Catecholamines, Laparoscopy, Myelolipoma.

\section{Introduction}

Myelolipoma is an uncommon, benign tumor, that is composed of mature adipose tissue along with hematopoietic elements [1,2]. Although myelolipomas do not classically produce any hormones, they may coexist with a metabolically active adrenal adenoma, usually producing excess cortisol [3]. This lesion is usually located in adrenal glands, but has been found at other localizations, such as pelvis, retroperitoneum and thorax [4]. In the past, adrenal myelolipoma was primarily detected at autopsy and incidence ranged from $0.1-0.4 \%$ [5]. Recently, with the widespread use of various imaging methods, such as ultrasonography, computer tomography and magnetic resonance imaging, incidental detection of adrenal myelolipoma has become more common (10-15\%) [6]. The majority of these incidentalomas are unilateral, small and asymptomatic although large size tumors can occur with bleeding complications that can be fatal $[7,8]$. The laparoscopic approach is technically challenging, although it can be performed by an experienced team. We present a case report of a giant myelolipoma that was removed by laparoscopy.

\section{Case Report}

A 37 years old man was referred from his primary care physician to the surgical department because he had an abdominal ultrasound showing a huge mass on the right adrenal gland with $98 \times 85 \times 96 \mathrm{~mm}$, consistent with a myelolipoma. On his past medical history there is reference to arterial hypertension and moderate alcoholic habits. He didn't have history of malignancy. He didn't have symptoms, such us palpitations, flushing, diarrhoea, diabetes, cramps, weight loss or anorexia. The physical examination was normal. The hemogram, cholesterol levels, 
glycated hemoglobin, thyroid function, electrolyte assay and liver function were normal. The functional study revealed a marginal elevation of plasmatic nor-adrenaline and catecholamines, with a normal renin, aldosterone and cortisol levels. The abdomino-pelvic tomography showed a nodular formation on the right adrenal gland with $103 \times 87 \times 80 \mathrm{~mm}$, with strong adipose tissue content, compatible with myelolipoma [Fig.1].

The MIBG scintigraphy [Fig.2] didn't reveal abnormal or increased uptake points of MIBG that could be related to an increased catecholamergic activity (such us pheochromocytoma or paraganglioma). Because of the size of the lesion and the possibility of malignancy the excision of the lesion was proposed. It was performed by laparoscopy, without any complications. The lesion was entirely excised and removed with an extraction bag, to avoid tumor seeding [Fig.3]. The patient was discharged on the $5^{\text {th }}$ post-operative day, without any complication. The anatomopathological examination revealed a nodular mass, with $310 \mathrm{~g}$ with $12 \times 10 \times 6 \mathrm{~cm}$. The histological examination revealed a benign mesenchymal neoplasm, with characteristics of myelolipoma. Malignant cells or pheocromocytoma images weren't identified. The patient was reassessed after 2 weeks and at 6 months post-surgery and he did not present any symptoms, so he was disharged to primary care setting.

\section{Discussion}

Myelolipoma is an uncommon tumor like lesion composed of a variable mixture of hematopoietic elements and mature fat [9]. The term "myelolipoma" was used by Oberling in 1929 [10] though the lesion was described earlier by Gierke in 1905 [11]. Sixty percent of myelolipomas have an adrenal localization, but can be found in a pre-sacral, thorax, retroperitoneum, pelvis, stomach and perianal localization [12]. The most acceptable etiology is that myelolipomas arise due to metaplasia of the reticuloendothelial cells of the

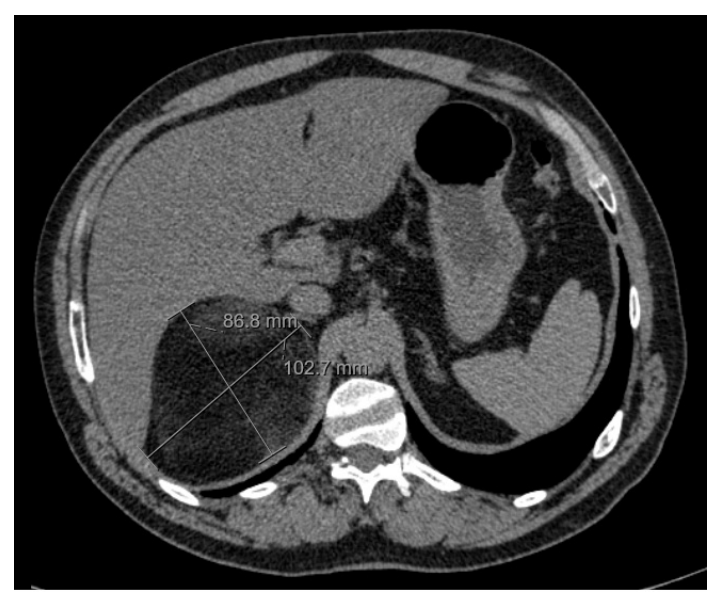

Fig.1: A nodule in right adrenal gland with strong adipose tissue content, compatible with myelolipoma.

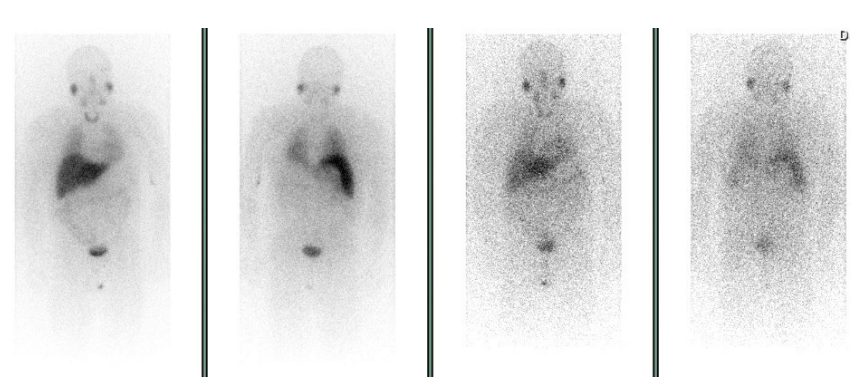

Fig.2: $M I B G$ scintigraphy showing no abnormal uptake points.

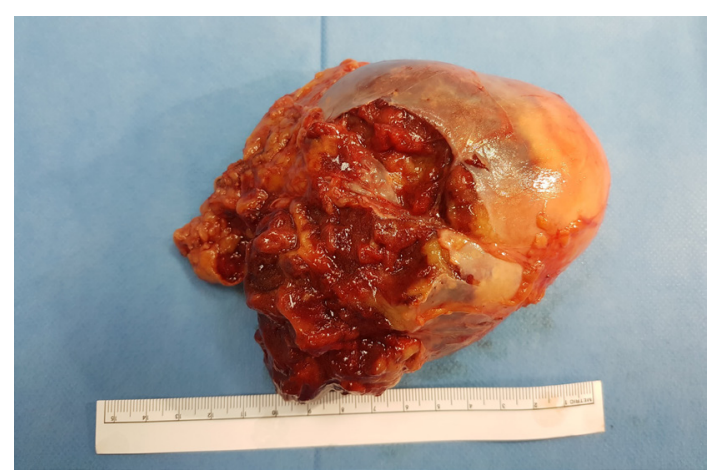

Fig.3: Enblock resection of tumor.

blood capillaries in the adrenal gland in response to stimuli such as chronic stress, infection, necrosis, or inflammation [13]. Usually they are nonfunctioning and asymptomatic, however they can be found in association with obesity, hypertension and endocrine disturbances, such as Addison disease, 
Cushing syndrome and hyperaldosteronism, or they can co-exist with adrenal hyperplasia or functioning tumors [14]. Adrenal myelolipoma has been reported as occurring in the $5^{\text {th }}$ to $7^{\text {th }}$ decades of life. It occurs in both genders with female predominance. The right adrenal gland is more commonly involved than the left [15].

In the past, these tumors were discovered at autopsy, with an incidence ranging from $0.1 \%$ to $0.4 \%$. Nowadays with the widespread use of radiological studies, the incidental detection of myelolipoma has become more common, constituting up to $10-15 \%$ of incidental adrenal masses [16]. The majority of these incidentalomas are unilateral, non-functioning and small, however bilateral cases have been reported [17]. Patients are generally asymptomatic. Nevertheless, when the tumors reach large dimensions, they can present symptoms related to the compression of neighboring organs, hemorrhage or even tumoral necrosis. Abdominal pain, hematuria and constipation are the most frequent symptoms observed. In some rare cases, large size tumors may have spontaneous rupture leading to severe hemorrhage or present with sepsis secondary to a large abcess $[18,19]$.

Small asymptomatic tumors less than $4 \mathrm{~cm}$ can be monitored expectantly since they pose little risk of spontaneous rupture or bleeding [20]. When the patients have tumors more than $4 \mathrm{~cm}$ or fastgrowing tumors, surgical resection should be the treatment of choice [21]. Since the introduction of laparoscopic adrenalectomy in 1992 by Gagner et al., this minimally invasive technique has gained worldwide acceptance and has become the gold standard for the removal of most small, benign lesions of the adrenal gland [22].

Laparoscopic adrealectomy for benign adrenal disorders is a safe procedure that is associated with significantly lower morbidity, shorter ileus and hospitalization, reduced postoperative pain, and a faster return to normal activity than the laparotomy [23]. Laparoscopic treatment of large tumors is still questionable due to the concern over the risk of malignancy as well technical difficulties. Traditionally, a tumor size of $6 \mathrm{~cm}$ to $8 \mathrm{~cm}$ has been considered as an upper limit for laparoscopic adrenalectomy [24,25]. It is known that the risk of malignancy increases with the size of the lesion [26]. The only specific contraindication for laparoscopic surgery is radiologic or intra-operative evidence of invasion of the peri-adrenal tissue by the tumor $[27,28]$.

Some authors suggest that the main limitation during laparoscopic dissection for large and potentially malignant adrenal tumors is incomplete resection and capsular disruption with increased risk of local recurrence and intraabdominal neoplasic seeding [29]. However these complication are also observed during open surgery. So, what is most important is the ability of the surgeon to perform a safe and complete resection [30].

\section{Conclusion}

The giant adrenal myelolipoma is a rare tumor. Laparoscopic adrenalectomy has become the gold standard in management of most adrenal masses. Even for giant adrenal masses, it can be done in a safe way, provided that is performed by an experienced laparoscopic team.

Contributors: SL: manuscript writing and patient management; CO: manuscript editing, and patient management. RA, MG, MN critical inputs into the manuscript and patient management. SL will act as a study guarantor. All authors approved the final version of the manuscript and are responsible for all aspects of the study.

Funding: None; Competing interests: None stated.

\section{References}

1. Nikumbh DB, Kshirsagar AY, Desai SR, Pallavi AS, Roopali KM, Wader JV. Giant adrenal myelolipoma. Am J Case Rep. 2011;12:83-86.

2. Lario MCC, Alonso BC, Peribáñez MJG, García EF, Atance JLVA. Mielolipoma suprarreal derecho gigante. Arch. Esp. Urol. 2006;59(9):911-913.

3. Hisamatsu H, Sakai H, Tsuda S, Shigematsu K, Kanetake H. Combined adrenal adenoma and myelolipoma in a 
patient with Cushing's syndrome: case report and review of the literature. Int J Urol. 2004;11:416-418.

4. Sen R, Gupta S, Parmar P, Brar K, Gilotra M, Gupta V. Giant adrenal myelolipoma: A rare case report and review of literature. J Integr Nephrol Androl. 2017;4:60-62.

5. Olsson CA, Krane RJ, Klugo RC, Selikowitz SM. Adrenal myelolipoma. Surgery. 1973;73:665-670.

6. Park BH, Lee SL, Seo KJ, Bae SR, Lee YS, Kang SH, Han $\mathrm{CH}$. Laparoscopic hand-assisted adrenal sparing surgery for giant adrenal myelolipoma: A case report. Int Surg. 2017;102:469-472.

7. Wani NA, Kosar T, Rawa IA, Qayum A. Giant adrenal myelolipoma: incidentaloma with a rare incidental association. Urol Ann. 2010;2:130-133.

8. Roldán JO, Baenaa BM, Paz IP, Bolaños PI, Álvarez TM, Martínez AF. Mielolipoma adrenal gigante: revisión a propósito de un caso. Endocrinol Nutr. 2008;55:130141.

9. Wagnerová H, Lazúrová I, Bober J, Sokol L, Zachar M. Adrenal myelolipoma. 6 cases and a review of the literature. Neoplasma. 2004;51:300-305.

10. Oberling C. Les formations myelolipomateuses. Bull Assoc Fr Etud Cancer. 1929;18:234-246.

11. Gierke E. Uber Knochenmarksgwebe in der Nebenniere. Zeiglers Beitr Path Anat. 1905;7:311-324.

12. Gac P, Cabané P, Klein E, Seymur C, Segura P. Mielolipoma suprarrenal gigante. Rev Chil Cir. 2012:64:292-296.

13. Nakayama Y, Matayoshi N, Akiyama M, Sawatsubashi $\mathrm{Y}$, Nagata J, Hisaoka $\mathrm{M}$, et al. Giant adrenal myelolipoma in a patient without endocrine disorder: A case report and a review of the literature. Case Rep Surg. 2018;2018:4854368.

14. Nail GA, Aguiar LC, Gimenez VR. Mielolipoma gigante bilateral da glândula adrenal. J Bras Patol Med Lab. 2007;43:265-268.

15. Shanthi V, Rao NM, Chaitanya B, Krishna BAR, Mohan KVM. Adrenal myelolipoma: A rare case report. J Dr NTR Univ Health Sci. 2012;1:124-126.

16. Ramirez M, Misra S. Adrenal myelolipoma: To operate or not? A case report and review of the literature. Int J Surg Case Rep. 2014;5(8):494-496.

17. Mondal, A, Chakrabarti DK, Basu A, Kela H. Bilateral adrenal myelolipoma: A Case Report. Hellenic. Journal of Surgery. 2017;89:160-162.

18. Costa SRP, Horta SHC, Henriques AC. Giant adrenal myelolipoma with a spontaneous rupture: report of a case. Einstein. 2009;7:357-360.
19. Kumar A, Jayant K, Prasad S, Agrawal S, Parma KM, Roat $\mathrm{R}$, et al. Rare adrenal gland emergencies: a case series of giant myelolipoma presenting with massive hemorrhage abscess. Nephrourol Mon. 2015;19;7(1):e22671.

20. Daneshmand S. Quek ML. Adrenal myelolipoma: Diagnosis and managemet. Urol J. 2006;3:71-74.

21. Yang Y, Ye L, Yu B, Guo J, Liu Q, Chen Y. Two case reports of bilateral adrenal myelolipomas. World J Cli Cases. 2015;3(9):853-860.

22. Hirano D, Hasegawa R, Igarashi T, Satoh K, Mochida $\mathrm{J}$, Takahashi S, et al. Laparoscopic adrenalectomy for adrenal tumors: A 21-year single-institution experience. Asian J Surg. 2015;38:79-84.

23. Hazzan D, Shiloni E, Golijanin D, Jurim O, Gross D, Reissman P. Laparoscopic vs open adrenalectomy for benign adrenal neoplasm. Surg Endosc. 2001;15:13561358.

24. Parnaby CN, Chong PS, Chisholm L,Farrow J, Connell JM, O'Dwyer PJ. The role of laparoscopic adrenalectomy for adrenal tumours of $6 \mathrm{~cm}$ or greater. Surg Endosc. 2008;22:617-621.

25. Zografos GN, Farfaras A, Vasiliadis G,Pappa T, Aggeli C, Vasilatou E, et al. Laparoscopic resection of large adrenal tumors. JSLS. 2010;14:364-368.

26. Bozkurt IH, Arslan M, Yonguc T, Degirmenci T, Koras $\mathrm{O}$, Gunlusoy B, et al. Laparoscopic adrenalectomy for large adrenal masses: Is it really more complicated? J Medl Sci. 2015;31:644-648.

27. Gagner M, Pomp A, Heniford BT, Pharand D, Lacroix A. Laparoscopic adrenalectomy: lesson learned from 100 consecutive procedures. Ann Surg. 1997;226:238247.

28. Ramacciato G, Mercantini P, La Torre M. Di Beedetti F, Ercolani G, Ravaioli M, et al. Is laparoscopic adrenalectomy safe and effective for adrenal masses larger than $7 \mathrm{~cm}$ ? Surg Endosc. 2008;22(2):516-521.

29. Lombardi CP, Raffaelli M, De Crea C, Boniardi M, De Toma G, Marzano LA, et al. Open versus endoscopic adrenalectomy in the treatment of localized (stage I/II) adrenocortical carcinoma: results of a multiinstitutional Italian survey. Surgery. 2012;152:1158-1164.

30. Agrusa A, Romano G, Frazzetta G, Chianetta D, Sorge V, Di Buono G, et al. Laparoscopic adrenalectomy for large adrenal masses: Single team experience. Int J Surg. 2014;12:S72-S74. 